\title{
EL PLAN DE ORDENAMIENTO TERRITORIAL Y EL PLAN ESPECIAL DE MANEJO Y PROTECCIÓN DEL PATRIMONIO EN LOS CENTROS HISTÓRICOS DE COLOMBIA: EL CASO POPAYÁN ${ }^{(\star)}$
}

\author{
THE LAND MANAGEMENT PLAN AND THE SPECIAL PLAN FOR THE MANAGEMENT AND \\ PROTECTION OF HISTORIC COLOMBIAN CENTERS: THE CASE OF POPAYÁN
}

\author{
DIANA RAMOS CHUQUIMIA ${ }^{(* *]}$ \\ Fecha de recepción: 30 de agosto de 2016 \\ Fecha de aprobación: 26 de noviembre de 2016
}

\begin{abstract}
RESUMEN
El artículo presenta la investigación de un estudio de caso sobre centros históricos latinoamericanos; se centra en Colombia, y sus herramientas más importantes para la protección y gestión del patrimonio cultural. Se aborda la relación conflictiva entre los fines del desarrollo urbanístico y las acciones que garantizan la protección y conservación de los centros históricos declarados de interés nacional. Estos fines y acciones se expresan en el discurso de dos planes: el Plan de Ordenamiento Territorial (POT) de 2002, formulado para el municipio colombiano de Popayán, aún vigente, y el Plan Especial de Manejo y Protección del Patrimonio (PEMP) de su centro histórico, aprobado en 2009. El actual escenario deriva de un análisis, cuyos resultados reflejan la tensión entre los objetivos de ambos planes: su desarticulación, la falta de implementación y los vacíos administrativos que han dificultado que el PEMP no haya sido desarrollado años después de haberse formulado.
\end{abstract}

\section{PALABRAS CLAVE}

Plan de Ordenamiento Territorial, Plan Especial de Manejo y Protección, centro histórico de Popayán

\section{ABSTRACT}

This article presents a research case study of a Latin American historical center in Colombia, and focuses on the country's most outstanding tools for the protection and management of cultural heritage. The troubled relationship between the purposes of urban development and the actions designed to ensure the protection, conservation and sustainability of declared cultural heritage, is broached; these can be seen in the discourse of two plans: the Land Management Plan (2002), formulated for the Colombian community of Popayan and still in effect, and the Special Plan for the Management and Protection of Heritage (SPMPH) of its historical center, approved in 2009. The analysis derived from a scenario whose results reflect the tension between the objectives of the plans: their disbandment, the lack of implementation and the administrative gaps that have hindered the development of the SPMPH years after its formulation.

\section{KEYWORDS}

Land Management Plan, Special Plan for the Management and Protection of Heritage, historic center of Popayan

(*) El presente artículo es parte del desarrollo de un trabajo de investigación del curso Taller de Intervención en Áreas, Conjuntos y Centros Históricos a cargo del MSc. Arq. José Hayakawa Casas. Pertenece al tercer ciclo de la Maestría en Conservación y Gestión del Patrimonio Edificado de la Unidad de Posgrado de la Facultad de Arquitectura, Urbanismo y Artes de la Universidad Nacional de Ingeniería (FAUA-UNI), cursado en el ciclo académico 2016-1. $\left.{ }^{(* *}\right)$ Arquitecta egresada de la Universidad Nacional del Altiplano. Actualmente cursa estudios de Maestría en Conservación y Gestión del Patrimonio Edificado de la Unidad de Posgrado de la FAUA-UNI. Ha trabajado en diversas instituciones públicas y privadas del sur del país. Contacto: dianarch56@hotmail.com 
En Colombia, se formulan Planes de Ordenamiento Territorial (POT) desde hace 16 años; ya es momento de evaluar su efectividad. Al mismo tiempo, surge una preocupación específica respecto del manejo de los Centros Históricos con Declaratoria Nacional, en relación con tanto sus instrumentos de gestión y financiación como, especialmente, con su articulación al ordenamiento territorial urbano de los municipios.

Desde la promulgación de la "Ley General de Cultura” (Ley № 397 de 1997), se estableció que para la planeación y gestión de los Bienes de Interés Cultural (BIC) con declaratoria nacional, entre los que se encuentran los centros históricos, el instrumento es el Plan Especial Manejo y Protección (PEMP) -que fue incluido y ratificado en la Ley No 1185 de 2008-. La misma ley ratificó que los centros históricos con declaratoria, mediante sus PEMP, debían ser incorporados al POT del municipio al que pertenecieran, y debían someterse a los procedimientos legales establecidos en sus respectivos Planes de Desarrollo Municipal para su revisión o modificación, según sea el caso.

De 44 centros históricos colombianos declarados de interés nacional, 18 de ellos tienen un PEMP revisado y aprobado por el Ministerio de Cultura mediante resolución. Entre ellos se encuentran Cundinamarca, Santander, Norte de Santander y Cauca, cuya capital de departamento, Popayán, cuenta con POT y PEMP aprobado. Más adelante presentaremos este último como estudio de caso.

Aunque las propuestas y normas aprobadas en el POT deben estar coherentemente articuladas al PEMP para garantizar la complementariedad de sus instrumentos de planeación y gestión, la Ley № 388 de 1997 establece que las normas de protección del patrimonio cultural son de superior jerarquía y, por lo tanto, priman sobre otras normas locales. De esta manera, en caso existan diferencias entre el POT y el PEMP de los centros históricos con declaratoria nacional, primarán las disposiciones consignadas en este último.

Sin embargo, el PEMP y el POT aún esperan poder articularse; “...no podemos someter más a la sociedad payanesa a espectáculos de descoordinación y de vacíos institucionales que únicamente desestimulan la inversión y generan complicaciones". (Maya, 2014, p. 20).

En efecto, en la práctica, en distintos municipios del país el PEMP y el POT no se han articulado como se esperaba. A la larga, como menciona Maya, al momento de intervenir en los centros históricos han surgido muchas contradicciones, descoordinaciones y vacíos institucionales; en muchos casos, el PEMP no se ha implementado después de su aprobación.

\section{El recorrido de las políticas públicas para la protección del patrimonio cultural inmueble en Colombia ${ }^{1}$}

Desde principios del siglo XX, la protección del patrimonio cultural en Colombia ha seguido un largo recorrido. Con el progresivo fortalecimiento de instituciones como la Biblioteca Nacional, el Museo Nacional, el Archivo General de la Nación y los predecesores del actual Instituto Colombiano de Antropología e Historia (ICANH), el patrimonio adquirió un papel preponderante en el panorama cultural del país. Estas acciones, dispersas y aisladas, comenzaron a estructurarse en 1959, con la expedición de la Ley № 163; por medio de esta se dictaron "medidas sobre defensa y conservación del patrimonio histórico, artístico y [de] monumentos públicos de la nación". Desde entonces, la gestión del patrimonio cultural ha pasado por diferentes entidades como el Consejo Nacional de Monumentos Nacionales, Colcultura, la Fundación para la Conservación

1. La información en la parte introductoria proviene de un resumen realizado por el autor del artículo titulado "El origen del patrimonio como política pública en Colombia, y su relevancia para la interpretación de los vínculos entre cultura y naturaleza" de Leonardo Garabito Gonzales, publicado en la Revista Opera de 2006 de la Universidad Externado de Colombia, en Bogotá, Colombia. 
del Patrimonio Cultural Colombiano, la Subdirección de Monumentos Nacionales de Invías y el Centro Nacional de Restauración, entre otros. Estas han sido instituciones de vanguardia en su momento, pero han desaparecido debido a, en gran parte, la evolución del concepto de patrimonio cultural y los diferentes procesos de modernización del Estado. Aparecieron nuevas tendencias internacionales; se adoptaron convenciones y cartas internacionales, en las que el patrimonio pasó de tener una connotación principalmente monumental a otra mucho más social e incluyente.

A partir de la aprobación de la Ley № 397 de 1997, "Ley General de Cultura", tuvo lugar una agenda legislativa y reglamentaria muy activa; se expidieron leyes y decretos que engrosaron el corpus de la legislación cultural, tanto en el ámbito nacional como en las entidades territoriales (departamentos, distritos y municipios). Esta nueva dimensión sociocultural de desarrollo adquirió gran valor como indicador de la calidad de vida y del bienestar humano; estos, a su vez, fueron involucrados dentro de los POT que derivan de la Ley № 388 de 1997, que señalan específicamente las zonas de protección urbano-patrimonial que pueden ser articuladas a los PEMP dentro del componente urbano.

Con el fin de mejorar la capacidad de manejo y protección del patrimonio cultural, se expidió la Ley № 1185 de 2008 y se elaboraron sus tres decretos reglamentarios relativos al Consejo Nacional de Patrimonio Cultural, al Patrimonio Cultural de la Nación de naturaleza material y al Patrimonio Cultural de la Nación de naturaleza inmaterial.

Con la expedición de estas normas, se trazaron nuevas funciones y responsabilidades tanto para el Ministerio de Cultura como para las demás instancias que forman parte del Sistema Nacional De Patrimonio Cultural (SNPC). Este sistema está compuesto por todos los actores involucrados en la gestión, protección y salvaguardia del patrimonio de la nación: las secretarías de cultura departamentales, distritales y municipales; los consejos departamentales y distritales de patrimonio cultural; los nodos regionales del Programa Vigías del Patrimonio Cultural; las escuelas-taller de oficios tradicionales; y otras entidades e instituciones, que incorporan en su misión el manejo y apropiación social del patrimonio cultural. Esto fue coordinado por el Ministerio de Cultura, "... para lo cual [este] fijará las políticas generales y dictará normas técnicas y administrativas, a las que deberán sujetarse las entidades y personas que integran dicho sistema" (Ley No 1185 de 2008, artículo 2, que modifica el artículo 5 de la Ley № 397 de 1997).

El objetivo principal de la política es lograr la apropiación del patrimonio cultural por parte de la ciudadanía y los demás actores del SNPC. En este sentido, la política brinda herramientas para una gestión social sostenible y responsable del patrimonio cultural en Colombia. Para ello se han planteado cuatro líneas de acción: i) conocimiento y valoración; ii) formación y divulgación; iii) conservación, salvaguardia, protección, recuperación y sostenibilidad; y iv) fortalecimiento institucional. Cada una de estas líneas está compuesta por una serie de estrategias que se enmarcan dentro de planes o programas de la Dirección de Patrimonio del Ministerio de Cultura, y siguen los lineamientos dados por la Ley № 1185 de 2008.

Con este marco, el Ministerio de Cultura ha puesto a disposición de sus municipios una serie de herramientas para la identificación básica, el inventario y la valoración del patrimonio cultural de la nación. También ha creado los mecanismos necesarios para la declaratoria de los Bienes de Interés Cultural (BIC). Las manifestaciones del patrimonio cultural inmaterial, del que forman parte los centros históricos, tienen un valor especial reconocido por su respectivo Consejo de Patrimonio. Para hacer efectivo este régimen, que las declaratorias de BIC requieren se busca evitar que estos procesos se hagan sin evaluaciones técnicas y conceptuales profundas; un paso fundamental es obtener el concepto previo favorable de los respectivos Consejos de Patrimonio Cultural, formular los Planes Espaciales de Salvaguardia para el caso del patrimonio inmaterial y formular los PEMP. Este último opera como instrumento del Régimen Especial de Protección de los BIC. 
Debido a sus especificidades y al tratamiento particular que requiere, y en el marco del reconocimiento legal, el Ministerio de Cultura ha formulado una política especial para la salvaguardia del patrimonio cultural inmaterial de los centros históricos: el Plan nacional de recuperación de centros históricos (PNRCH).

El PNRCH es el instrumento de planeación diseñado por el Ministerio de Cultura para recuperar y revitalizar los centros históricos colombianos. Se hace efectivo mediante la formulación e implementación de los planes especiales de manejo y protección, instrumentos de planeación definidos con la participación de actores públicos y privados de los ámbitos nacional, departamental y local; ello garantiza la sostenibilidad de dichos centros. Implica una metodología que se construye y aplica según las realidades y necesidades particulares de cada centro histórico, y cuenta, durante todo el proceso, con la participación de la ciudadanía.

\section{PEMP: vulneración de la autonomía territorial y descentralización del POT $^{2}$}

Cuando nacieron los POT en Colombia, cada municipio hizo un inventario de su patrimonio. Entonces, ¿por qué volver a empezar con otra estrategia como los PEMP?

Antes que nada, son dos instrumentos diferentes. El POT es un plan de desarrollo de todo el municipio, de todos sus ámbitos y componentes. El POT sirve, entre otras cosas, para coordinar las inversiones públicas y privadas sobre el territorio; verificar la correcta aplicación de las normas que privilegien el bien común; identificar, delimitar y preservar los elementos básicos del medio ambiente que forman parte del patrimonio ecológico y cultural; organizar y coordinar los recursos públicos para la ejecución de proyectos y obras; y regular el uso equitativo y racional del suelo.

EI PEMP está centrado exclusivamente en la salvaguardia del patrimonio arquitectónico y urbano de los centros históricos, previamente declarados y protegidos, del ámbito nacional. Son estrategias para que esos centros históricos o sectores de ciudad se desarrollen; sin embargo, hay mucho que no le compete al PEMP, como los temas socioeconómicos o medioambientales que, no obstante, sí puede tomar en cuenta como elementos de amortiguamiento del centro histórico. Lo que queda claro es que el PEMP, al ser una norma de mayor jerarquía, obliga al POT a incluirlo inmediatamente en sus planes.

Por otro lado, es preciso anotar que el POT, según el Acuerdo 06 de 2002, en cuanto a medidas de protección del centro histórico, no establece las políticas necesarias y efectivas para la conservación de los BIC. Por ejemplo, en su artículo 71, solo plantea la necesidad de formular un Plan parcial para el centro histórico, previa realización de un plan especial de protección que fije las políticas de manejo del casco antiguo de la ciudad.

Entonces, ¿cómo encajarían el PEMP y el POT? En cuanto a la articulación de PEMP y el POT, el artículo 71 del Acuerdo 006 del POT de 2002 confunde las figuras de Plan Parcial y PEMP. El PEMP es jerárquicamente superior a los Planes Parciales. Pretender que con un solo plan parcial se puede proteger todo el centro histórico resulta irracional. Pareciera que se plantea que para cada plan parcial se requerirá un PEMP. Así, Montaña y Frenchy (2012) lo confirman:

...el ordenamiento territorial, al ser un ejercicio que termina por reglamentar patrones de ocupación y uso del suelo, no puede ser ajeno a las dinámicas económicas que se dan en el centro histórico de una ciudad. Los Planes Especiales de Manejo y Protección (PEMP), pueden limitar usos y edificabilidad de los Planes de Ordenamiento Territorial. Es por esta razón

2. La información de esta sección proviene de la Monografía de Grado del trabajo titulado Planes especiales de manejo y protección para centros históricos y su incidencia en los principios de descentralización y autonomía de los municipios y distritos, presentada en la Facultad de Ciencias Jurídicas Derecho Urbanístico de la Pontificia Universidad Javeriana de Bogotá, en agosto de 2012. 
que, en muchas ocasiones, el PEMP vulnera el principio de la autonomía y la descentralización administrativa local...

[Por otro lado], se reconocen los derechos adquiridos para propietarios de predios, y de aquellos con derechos de ocupación de espacios públicos por ley, pero vemos como el PEMP se extralimita en sus competencias, ya que, si bien el Concejo Municipal puede reglamentar los usos del suelo y dictar las normas necesarias para el control, preservación y defensa del patrimonio cultural del municipio, no puede referirse a derechos constitucionales que requieren debate según sea el caso. Así mismo, tampoco se puede plantear derechos adquiridos en ocupación de espacios públicos, y menos cuando el espacio público es de todos. Las normas culturales por ser de superior jerarquía prevalecen sobre los intereses individuales. Debe hacerse revisión del POT, para incluirse la normativa contenida en su PEMP, entre otras una nueva delimitación, etc.... (p. 66)

A nivel macro, el artículo 313 de la Constitución Política indica que "corresponde a los consejos reglamentar el uso de suelo dentro de los límites que fije la ley, y vigilar y controlar las actividades relacionadas con la construcción y enajenación de inmuebles destinados al uso de vivienda". Además, el artículo 11 de la Ley № 397 de 1997 ratifica la incorporación de los PEMP a los POT:

Los PEMP relativos a bienes inmuebles deberán ser incorporados por las autoridades territoriales en sus respectivos planes de ordenamiento territorial. Pueden limitar los aspectos relativos al uso y edificabilidad del bien inmueble declarado de interés cultural y su área de influencia, aunque el POT ya hubiera sido aprobado por la respectiva autoridad territorial.

Con esto, podemos afirmar que la razón de ser del PEMP es la defensa del patrimonio; la del POT, el equilibrio de intereses; además, se habla de la incorporación del PEMP dentro de los planes de desarrollo municipales, con sus respectivos presupuestos e inversiones y su deber es limitar, mas no reglamentar; podrían cometerse delitos de prevaricato y una falta disciplinaria por usurpación de funciones.

En el Decreto № 763 de 2009 en su artículo 20, referido al nivel permitido de intervención que el Ministerio de Cultura establece y tiene competencia para las obras que se quieran realizar respecto a la conservación de los valores de los inmuebles y su zona de influencia. El nivel más riguroso y proteccionista es la 'conservación integral' que, generalmente, concierne a toda el área afectada. Dentro de los niveles dos, de tipo arquitectónico, y tres, de tipo conceptual, se rigen con norma urbana del municipio e intervienen, generalmente, en la zona de influencia o, en ocasiones, en una pequeña parte de los bordes de áreas afectadas. No obstante, el Ministerio de Cultura no tiene la capacidad institucional de proteger y conservar todos los inmuebles que forman parte del centro histórico. Por ésta razón, claramente el tema de la "autonomía territorial" y "descentralización" entra en conflicto sobre quien es el competente al momento de realizar acciones en cada nivel, si el Ministerio de cultura o el PEMP o el municipio y sus entes respectivos.

Así es como aparece un conflicto sobre cuál organismo es el competente o cuál debe entrar a sancionar, ya que el Ministerio de Cultura tiene competencia directa sobre la declaratoria de los BIC, y sobre todo el centro histórico y determinado inmueble en el nivel 1, pero tiene declaratoria municipal sobre un solo bien. Este es un tema recurrente en todos los PEMP.

En cuanto al cumplimiento de obligaciones que impone el PEMP al alcalde, existió una concertación y un convenio previos sobre cómo desarrollarlo. El texto de la resolución fue construido conjuntamente entre el Ministerio de Cultura y el alcalde de Popayán, pese a que solo fue firmado por el primero. El PEMP de Popayán contempla varias obligaciones que podrían ser objeto de acciones de cumplimiento legales. Se establecen algunos reglamentos locales que de no estar concertados vulneran las competencias del Concejo del Municipio, así como la autonomía territorial y la descentralización administrativa. Se pueden ver, en la resolución, términos como 'deberá' y 'establecerá', o 'expedirá', que no solo se interpretan como una orden, sino que indican que se comparte una responsabilidad. 


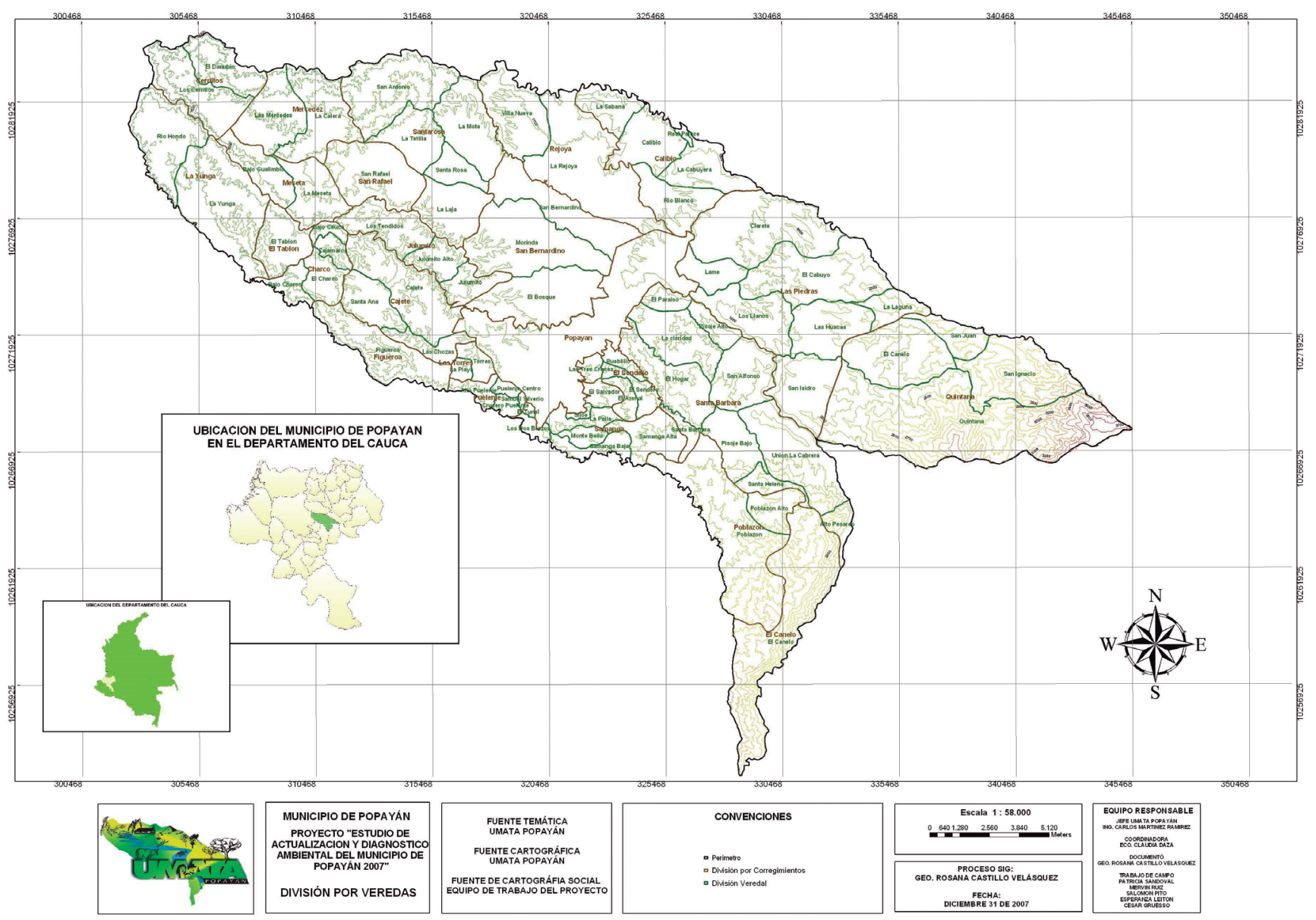

Figura 1. Ubicación del Municipio de Popayán en el Territorio colombiano Fuente: www.popayan.gov.co, 2016.
El artículo 36 del PEMP de Popayán, sobre “Unidades Arquitectónicas" plantea en su primera sección que "...los proyectos de intervención en predios que hacen parte de una unidad arquitectónica DEBERÁN ser desarrollados teniendo en cuenta la edificación en su conjunto....". Este es un caso claro en el que se vulnera la autonomía territorial, porque la Nación, a través de Ministerio de Cultura, intenta decir que serán ellos quienes tendrán dentro de sus funciones las tareas de fiscalizar. Se debió ajustar para especificar si se trataba de un BIC nacional. De esta manera, sí sería competente el Ministerio de Cultura, pero si son BIC de carácter municipal, el único que podría aplicar sanciones es el municipio o el organismo al que el municipio le habría delegado esta función.

Así mismo, la normatividad cultural establece que la declaratoria y el manejo se harán en virtud del principio de coordinación; las autorizaciones previas para intervenciones le corresponderán a quien efectúo la declaratoria. En este caso, si la declaratoria de todo el centro histórico es un BIC de carácter nacional, y si se trata de un predio que es BIC municipal incluido dentro de ese centro histórico, debe tenerse en cuenta que el PEMP es una norma especial y que al especificarse sus niveles de intervención, contenidos en el Decreto № 763 de 2009 en el artículo 20, se estableció que es el Ministerio de Cultura el que reglamenta dichos niveles para BIC, tanto nacionales como para territoriales.

En cuanto al espacio público, el artículo 69 del PEMP plantea que se permiten realizar actividades culturales y comerciales de carácter temporal, como ferias, mercados y espectáculos en los espacios públicos. También establece que la Oficina Asesora de 
Planeación Municipal expedirá la normativa que determinará los lugares, los horarios y los tiempos aptos para dichas actividades.

Al respecto se indica que el Ministerio de Cultura, al dar una orden con la palabra 'expedirá', vulnera la autonomía territorial: no lo recomienda sino lo ordena. En el artículo 311 de la Constitución Política se establece que esa función está a cargo de la Secretaria de Planeación. Este artículo también señala lo siguiente:

...al municipio como entidad fundamental de la división político-administrativa del Estado le corresponde ordenar el desarrollo de su territorio, promover el mejoramiento social y cultural de sus habitantes, y cumplir las demás funciones que le asignen la Constitución y las leyes. (p. 85)

Así como en este artículo, hay muchos más en el PEMP donde se plantea como obligación la palabra 'establecerá'. Por ejemplo, en cuanto a 'construcción prioritaria', el Art. 31 del PEMP plantea un listado de los inmuebles que 'deberán' desarrollarse conforme a lo determinado en la Unidad de Gestión respectiva. Esta es una competencia municipal que debe incorporarse de inmediato al POT para que sea efectiva en relación al Plan Nacional de Desarrollo.

Por estas razones, los temas de 'autonomía territorial'y 'descentralización' se tratan claramente en el POT como instrumento de apoyo a la gestión planificadora, y como una política del Estado para impulsar la descentralización y la cultura de la participación ciudadana establecida en la Constitución Nacional, que implica que las entidades municipales hagan uso de sus recursos y su capacidad de gestión.

Sobre la delimitación del centro histórico, se desarrolla otra disyuntiva. Existe una delimitación inicial en la declaratoria en la Ley № 163 de 1959 que señala que un sector histórico no solo debe incluir un conjunto representativo del período colonial y los años de la Independencia. No obstante, la delimitación dada en la Ley № 397 de 1997 comprende los bienes inmuebles de interés cultural de todas las épocas, e incluye edificios y barrios modernos significativos para la evolución urbana, la historia y la cultura de la ciudad. La delimitación del Acuerdo de 2002 está realizada de acuerdo a lo contemplado en el POT de Popayán, y la última delimitación, planteada en el PEMP de 2009, incluye algunos barrios modernos especialmente significativos, para protegerlos y para preservar dos cerros tutelares que se encuentran en ellos, como se señala en los planos de delimitación y área de influencia.

\section{El desafío del PEMP para la protección del centro histórico payanés}

Popayán, la capital del departamento del Cauca, se ubica en la parte suroeste de Colombia y fue fundada en 1537 (Figura 1). Es una de las ciudades más privilegiadas del país, ya que cuenta con un incalculable patrimonio histórico, artístico, ambiental y cultural; este es un gran activo que beneficia a sus habitantes. El patrimonio cultural de Popayán comprende, de acuerdo a los estudios del PEMP, iglesias, conventos, casas urbanas, haciendas, plazas, plazoletas, etc. (Figura 2), así como manifestaciones arraigadas como las procesiones de Semana Santa; estas hacen que el centro histórico sea de gran valor.

Mediante la Ley № 163 de 1959 se declaró Monumento Nacional el centro histórico de Popayán. Posteriormente, mediante la Ley № 397 de 1997, se declaró BIC, lo cual se ratificó en la Ley № 1185 en 2008. (Figura 2)

El Plan Nacional de Recuperación de Centros Históricos propuso recuperar los sectores urbanos del ámbito nacional declarados como BIC mediante una estrategia; gracias a esta el Ministerio de Cultura, el departamento del Cauca y la Alcaldía de Popayán suscribieron el Convenio № 837 de 2003 con el objetivo de "cooperar en el cumplimiento de funciones administrativas aunando esfuerzos nacionales, departamentales y municipales con el fin de elaborar el Plan Especial de Protección PEP del Sector Antiguo del Municipio y su área de influencia" (p. 1). 

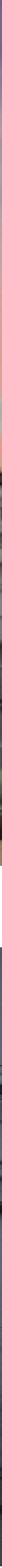

Figura 2. Arriba: la Catedral Basílica de Nuestra Señora de la Asunción. Abajo, de izquierda a derecha: el puente el Humilladero -construido en 1873- y una calle tradicional del centro histórico de Payanes Fuente: www.flickr.com, 2016. 


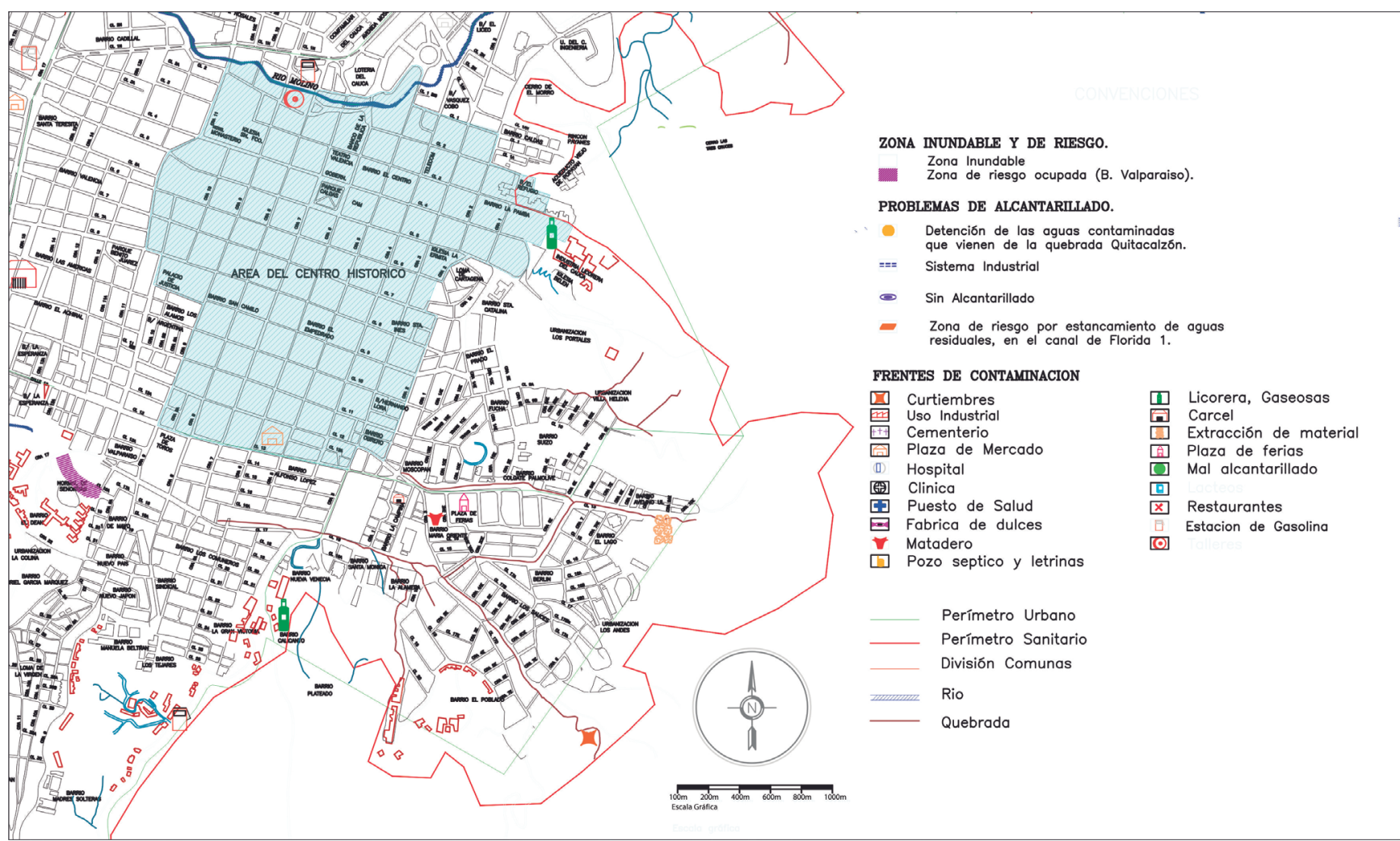

Posteriormente, en 2005, suscribieron el Convenio № 1235, mediante el cual se dio pase a la elaboración de la Fase II del PEP del centro histórico de Popayán, conforme la metodología establecida por el Ministerio de Cultura. Más adelante, gracias a la Ley No 1185 de 2008, el PEP pasa a ser PEMP, ya que se le agregan herramientas de gestión.

El Acuerdo 7 de 2002 del Concejo de Popayán adopta la delimitación y reglamentación del centro histórico de Popayán incluido en el POT. Con la resolución 2432 de 2009, se aprueba el PEMP del Sector Antiguo de Popayán declarado como BIC Nacional (Figura 3 y 4).

Al respecto, el especialista Caldas (2015) afirma lo siguiente:

El PEMP de Popayán, fue elaborado por un grupo profesional multidisciplinario. Además de proteger y preservar, este instrumento de gestión busca revitalizar el centro histórico. El PEMP [compuesto por normas y proyectos] define un centro histórico activo, sostenible, de encuentro, con generoso espacio público y movilidad, en el que se privilegie la vivienda y se combine con las actividades comerciales, artesanales, institucionales y académicas. El buen uso de los recursos existentes y de los que se puedan rescatar dentro del sector histórico, se convierten en un capital para usufructuar en bien de todos y transferirlo de generación en generación. EI PEMP apunta a valorizar y viabilizar la protección del patrimonio, la cual sólo será posible si este es rentable y útil a la sociedad, y si su conservación se articula con mecanismos de gestión y financiación que permitan obtener los recursos necesarios para su recuperación. Se trata de impulsar un proceso de economía patrimonial consciente, en una sociedad que valora su patrimonio y le dedica esfuerzos en cuanto a inversión, lo que se traduce en trabajo y empleo que permite a su vez que el legado perdure socialmente. (párr. 4)

En este PEMP se han comprometido las partes que firmaron tal convenio. Esto no ha ocurrido en otros PEMP de centros históricos en los que la autoridad distrital o municipal presenta la formulación del PEMP con base en estudios técnicos que han contrata-
Figura 3. Delimitación del centro histórico según resolución 2432 de 2009 e identificación de riesgos en zonas de amortiguamiento

Fuente: Secretaria de Planeación de Popayán, Alcaldía de Popayán, Gobernación del Cauca, 2016. 
devenir Vol. 3, Nº, JULIO-DICIEMBRE 2016, PP. 63-78 - Estudios I ISSN 2312-7570

UNIVERSIDAD NACIONAL DE INGENIERÍ, LIMA

Figura 4. Vista panorámica del centro histórico de Popayán

Fuente: www.popayancultural.com, 2016.

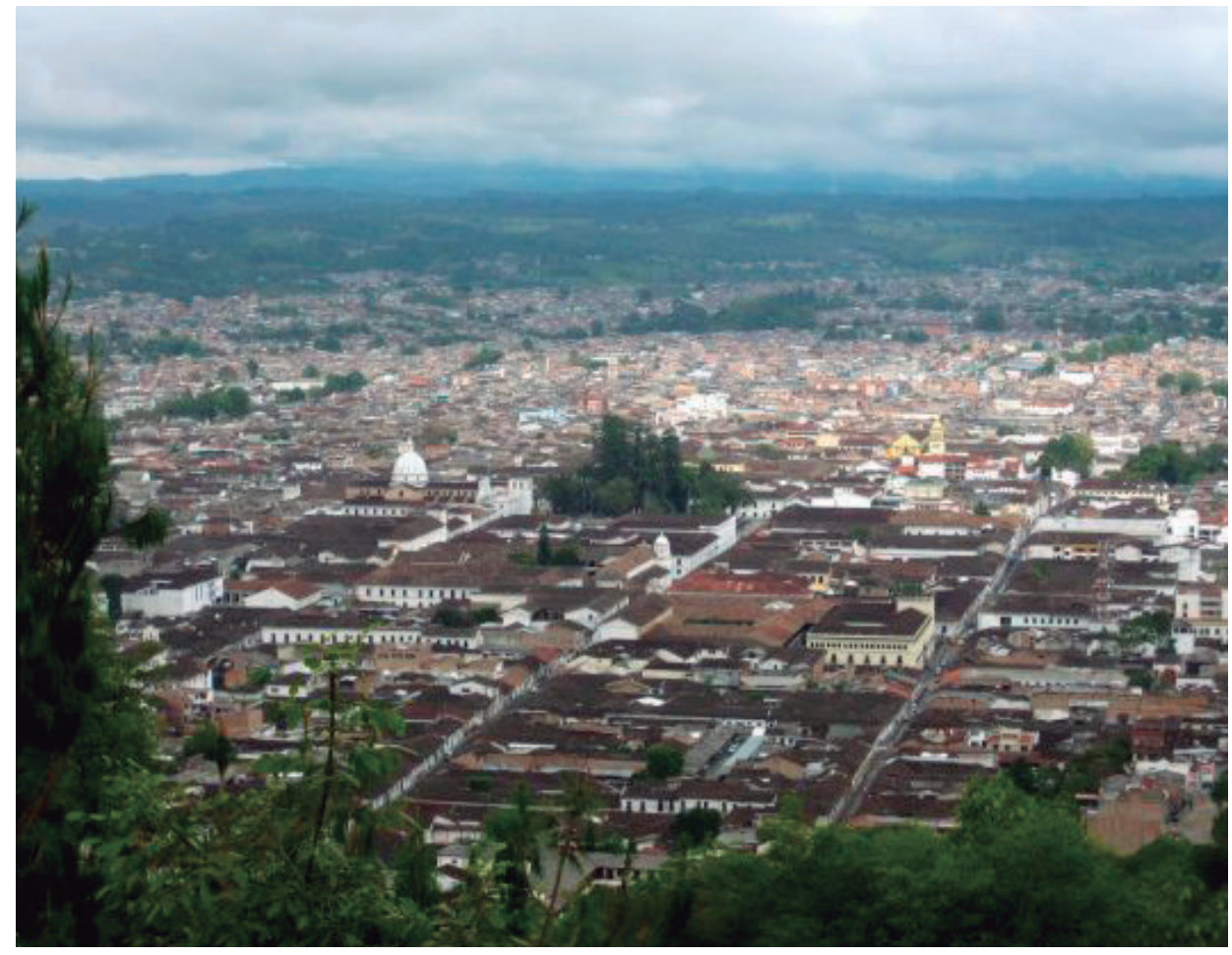

do, y donde estos se acomodan a sus intereses; luego, llegan al Ministerio de Cultura, y son criticados por no cumplir los objetivos del PEMP y las normas culturales. Según Montaña \& Frenchy (2012),

....el Ministerio de Cultura se esfuerza por ingresar a la formulación con el aporte de recursos, así podrá contratar consultorías imparciales. Pero la mejor solución es concertar, suscribir un Convenio así cuando se logre ejecutar el PEMP se harán realidad todas las directrices, programas y proyectos allí planteados. (p. 68

Por otro lado, Caldas Verona (2015) sostiene lo siguiente:

...en el PEMP Popayán se demostró voluntad de la administración municipal y de la comunidad para preservar el Centro Histórico. Esto se refleja durante el proceso de concertación previo con el Municipio y en este caso con el Departamento del Cauca, que quiso participar para aunar esfuerzos económicos.... (párr. 9)

Sin embargo, han transcurrido seis años y durante ese tiempo, hasta hoy, jel PEMP increíblemente no se ha comenzado a implementar por falta de un ente gestor!

No es el único caso. Se trata de un problema nacional. Otras ciudades como Barichara, Buga, Mompox, Villa de Leyva, etc., también con Sectores Históricos valiosos, apenas han comenzadas a estudiar cómo gestionar la implementación de sus PEMP.

Según el documento 'Formulación e Implementación de Planes Especiales de Manejo y Protección Bienes Inmuebles de Interés Cultural', redactado por el Ministerio de Cultura (2011) sobre el responsable de la implementación y del seguimiento de un PEMP,

...la implementación efectiva del Plan de Acción y de Inversiones, la cual deberá integrar a todos los actores involucrados. Esta base institucional se denomina 'ente gestor', y su principal función es la de liderar la ejecución del PEMP. (p. 52) 
La responsabilidad de implementación es homóloga a la de formulación; por lo tanto, para los BIC del grupo urbano, la implementación del PEMP corresponde a las autoridades distritales o municipales del territorio en donde estos se localicen. Las autoridades competentes, departamentales y nacionales, podrán concurrir, en este caso, mediante el aporte de recursos. (p. 53)

Con respecto a ello, la confusión de los funcionarios municipales es, de algún modo, justificable. No se dirigen con nombre propio a nadie. De algún modo, se presta a una doble interpretación si se desconoce qué organismos municipales se encargan de la elaboración de un PEMP. Cabe resaltar que los que intervienen en la formulación del plan son actores multidisciplinarios, entre estatales y privados.

También señala un 'ente rector' que no alude a ningún organismo en especial. Este 'ente' pareciera tener significado literal: "cosa o ser que tiene existencia real o imaginaria" (ente, 2016). Además, se indica que es obligación de los 'actores involucrados' darle una denominación especial.

Ante tal preocupación, surgen otras interrogantes: ¿por qué ha habido mucha dificultad para implementar el PEMP específicamente en Popayán? ¿Ha habido falta de interés político? Por ejemplo, el hecho de que el comercio sea el sector social que rige el centro de la ciudad histórica, y que para la mayoría de comerciantes y dueños de negocios prime su ganancia, ha hecho que se pierda el sentido de pertenencia y la necesidad de proteger el sector histórico. Esto se ha acrecentado producto del desinterés de los distintos estamentos sociales y representantes políticos por conservar este patrimonio.

A todo ello se suma que el proceso de socialización, ya que, según opiniones de los especialistas payaneses, hasta 2014 el PEMP 2009 no se había socializado, y menos aún implementado como principal herramienta de gestión para recuperar y revitalizar el centro histórico.

Este es un hecho bastante curioso, ya que una de las primeras estrategias que el mismo PEMP establece en su corpus es la de su divulgación. Obviamente, una ciudadanía que hubiese sido informada sobre los beneficios que le trae tal plan exigiría su implementación, mas no se han mostrado esos resultados sobre su divulgación.

Ante tal indiferencia, entraron a tallar diversas instituciones, 'los actores involucrados. Tras una histórica sesión conjunta de la Asamblea Departamental del Cauca, con el Concejo Municipal, en julio de 2013, se tomó la decisión, casi unánime, de implementar el PEMP y dar el primer paso con la creación del perfil del 'ente gestor', labor que el alcalde de aquel entonces encomendó a la Veeduría Ciudadana del patrimonio histórico y natural de Popayán (Veer Popayán) del sector histórico, designada la principal encargada de coordinar con un grupo de profesionales y funcionarios especializados en el tema.

Es así que, después de algún tiempo, Veer Popayán desempolvó el PEMP; se le empezó a estudiar, a profundizar en él y a tratar de ponerlo en vigor tras seis años de olvido.

\section{La propuesta del 'ente gestor'3}

Han pasado dos años desde que Veer Popayán concertó con la alcaldía de Popayán la entrega de una propuesta y la toma de decisiones acerca del ente gestor del PEMP de Popayán. La entrega de la propuesta se hizo finalmente en julio de 2014 y se encuentra actualmente en manos de la Oficina de Planeación Municipal. De la misma manera,

\footnotetext{
3. El proyecto "Mesa Larga-Mesa Larga", propuesto en junio de 2014, presenta la integración de tradiciones campesinas e indígenas en la articulación de actividades urbanas; hace énfasis en la tradición gastronómica de las mesas largas, formas de restaurantes populares asociadas a las galerías de la ciudad y puestos de ventas en espacios públicos. La idea es manifestar la recuperación y el desarrollo de estas culturas en la articulación de un corredor cultural-gastronómico interconectado, y en coexistencia armoniosa con las otras funciones urbanísticas de la ciudad. Es uno de los proyectos estratégicos para articular de manera demostrativa el PEMP.
} 
se entregó una propuesta para el macro proyecto "Mesa Larga-Mesa Larga", proyecto bandera del PEMP, en el mes de junio de 2014, producto de una mesa de trabajo entre la Oficina de Planeación Municipal y varios actores ciudadanos.

El Ministerio de Cultura envió observaciones y modificaciones del PEMP que están pendientes de ser contestadas por la Oficina de Planeación Municipal. Sin embargo, para los mismos encargados de la Oficina de Planeación Municipal, la propuesta del "ente gestor" carece de sustentación suficiente para ser aprobada por el alcalde.

A continuación, se exponen algunos resultados de la primera observación de la actuación de Veer Popayán con respecto del PEMP y con ello, algunas dudas y preguntas que surgieron durante el proceso:

1. La propuesta del ente gestor de Veer Popayán no ofrece más elementos de juicio que el proyecto original elaborado por el equipo de profesionales encargados, ya aprobado por las autoridades competentes hace seis años. Más que nada, se ha puesto énfasis en ilustrar la importancia de la política cultural del patrimonio intangible de Popayán para tomar decisiones políticas, ya que el patrimonio físico, en buena medida, ha sido destruido en el terremoto de 1983 y, por lo tanto, ya no existe mucho que valga como auténtico. Por otro lado, da paso a la desconfianza institucional. Sodemann (2014) reafirma que "para la constitución de una oficina con poco personal cuya función no está claramente establecida, ni su capacidad y responsabilidad, como para generar la constitución de un 'ente gestor' con capacidad profesional y financiera que respondería a las exigencias de un programa de conservación, recuperación y reformación urbanístico del centro histórico de Popayán [...]" (párr. 4).

2. La propuesta de Veer Popayán parte de la idea de que la recuperación, conservación y reforma del centro histórico delimitado en el proyecto original del PEMP de Popayán, por sí misma, representa el proyecto urbanístico decisivo que desencadenará en procesos de desarrollo cultural y socioeconómico importantes no solo para todo Popayán, sino para la región caucana entera. Una de las fuerzas motrices es la voluntad de hacer realidad el aparente sueño que debería ser el turismo. La visión de realizar este sueño no se justifica con verificaciones o estudios concretos, ni se caracterizan conceptos, etapas y posibilidades de financiamiento del programa turístico del futuro.

3. El centro histórico abarca zonas de la ciudad en pleno descenso urbanístico. Este, en particular, es el caso del barrio El Empedrado y del barrio Alfonso López. El PEMP no permite renovaciones urbanísticas sino reformas arquitectónicas. Esto significa que se pueden reformar los edificios sin alterar su volumetría. No hay estudios socioeconómicos que ilustren la situación financiera de los propietarios de inmuebles y su capacidad económica para asumir inversiones, pero salta a la vista que muchos edificios se encuentran semiabandonados. Si se toman el costo por $\mathrm{m}^{2}$ de área reconstruida del mercado inmobiliario de Popayán como referencia, una casa reformada de $200 \mathrm{~m}^{2}$ costaría 200 millones de pesos (equivalente a 220 mil nuevos soles).

4. Al analizar los conjuntos urbanísticos básicos como las cuadras, manzanas o sectores, una cuadra típica en el barrio El Empedrado, por ejemplo, puede consistir de unos veinte lotes. Un ente gestor debería tener la capacidad de asumir la reforma de por lo menos una cuadra. Esto significa que debe disponer de un capital bastante importante para poder ejecutar la reforma básica urbana de una cuadra. ¿De dónde y cómo surgiría este capital? Ni el PEMP ni, menos aún, la propuesta de Veer Popayán dan pistas concretas.

5. Aparentemente, Veer Popayán decidió organizar una gran convocatoria entre contribuyentes particulares a partir de la lista de supuestos interesados en contribuir voluntariamente al capital del ente gestor que agregó a su propuesta. No se conocen los resultados de las encuestas de estos futuros socios ni su disposición real para aportar el capital necesario. 


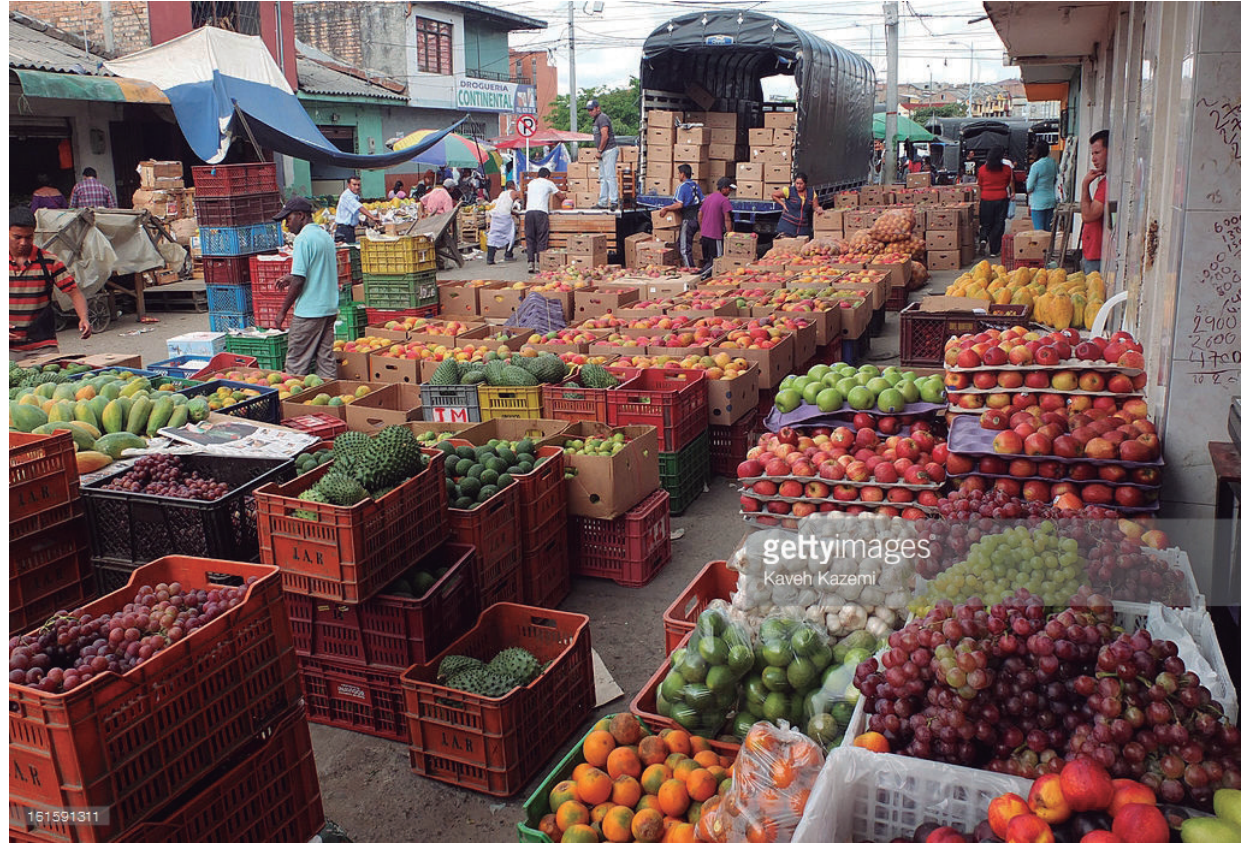

Parte de la renovación urbanística concierne a las áreas públicas. ¿Cómo se piensa financiar este aspecto? No hay datos concretos ni en el PEMP ni en la propuesta de Veer Popayán. Se habla de participaciones en planes de cofinanciamientos plurianuales municipales. También se considera cobrar una especie de impuesto a todos los ciudadanos para así financiar la renovación y conservación del centro histórico. ¿Está la población dispuesta y en condiciones económicas financieras de reunir el dinero para la conservación y reformación de espacios públicos? Si seguimos al plan pre-proyecto "Mesa Larga-Mesa Larga" se puede pensar en un plan plurianual por etapas que comience con la reforma del Parque Humilladero-Arboleda, siga con la reforma del Parque Mosquera para llegar a reformar el sector del Barrio Bolívar alrededor de la Galería Municipal, etc. No hay estudios arquitectónicos ni proyectos o preproyectos elaborados a la mano, pero cada etapa representa inversiones altas sin generar retorno de ingresos a corto plazo. Las ideas de cómo reunir el capital y sobre qué fuentes posibles existen son todavía muy vagas.

6. Sodemman, (2014) afirma que [...] un programa de renovación, conservación o de reformas urbanísticas, como aparece en el PEMP [...] no puede solamente escoger una parte de la ciudad, no importa que este sea el más deseado por un sector de la población payanesa. El turismo no surge de la nada. Debe haber productos previamente elaborados y bien organizados [...] Un centro histórico por sí solo, además, en descenso, no atrae. Hay que poner orden a toda la ciudad [...] Vías invadidas por un transporte individual desenfrenado no atrae a nadie. El uso de espacios públicos desordenado, tampoco. No se puede expulsar con la policía a todos los comerciantes informales, como algunos piensan. El centro histórico está invadido por comerciantes informales, porque es en el centro histórico donde se concentran las funciones económicas principales de la ciudad como son colegios, administraciones, bancos, oficinas, universidades, comercios, etc.... (párr. 11)

Esta invasión, por lo tanto, es expresión de la pauperización de la ciudad por migrantes pobres del campo y víctimas de la violencia rural, dos tercios de los cuales subsisten en la periferia tugurizada de Popayán y necesitan las ventas para sobrevivir. No basta estigmatizarlos como no deseados y mandarlos hacia la periferia de la ciudad, como las últimas
Figura 5. Comercio callejero informal de frutas en el barrio Bolívar Fuente: Raven Kazemi. Recuperado de www.gettyimages.org, 2016. 
administraciones municipales han insinuado. Por ser la mayoría absoluta, ellos son decisivos para las autoridades políticas en temporada de elecciones. Por otro lado, los payaneses tradicionales -conocidos como 'patojos'-no son más que el $10 \%$ de la población. ¿Serán tan apreciados por las mayorías como para que estas subordinen sus propias reivindicaciones culturales, económicas y sociales a las de un sector minoritario tradicional?

7. Un caso particular en el tema de riesgos es el Barrio Bolívar, barrio de influencia del PEMP, que está expuesto a inundaciones, inseguridad, hacinamiento de comercio informal, uso inapropiado del manejo del comercio al mayor, etc. El Plan Parcial decretado por la alcaldía carece de validez legal. El barrio Bolívar es el territorio ciudad-campo más importante del Cauca; concentra todo el comercio regional mayorista, por lo que merece un plan parcial que no rompa con su tradición, sino contribuya a su reforma.

Hasta la fecha, la administración municipal insiste en la reubicación de los comerciantes mayoristas formales (Figura 6) y gran parte de los revendedores informales, que migran desde la periferia a la ciudad con el conocimiento de que allí no pueden sobrevivir económicamente. Se insiste en un proyecto de renovación urbanístico implantado que no ha sido consultado con la población ni aprobado por el Concejo Municipal. Se confunde un programa de renovación urbanística con el de una reforma urbanística. El primero significa demolición y reconstrucción. El segundo permite conservar tradiciones valederas para dar empleo a muchas personas y generar un ambiente agradable tanto para la población residente como para turistas, a través de una reorganización del comercio.

8. Mucho se habla de participación ciudadana, pero no está claro quién tomará las decisiones en caso de que la financiación de proyectos que benefician al centro histórico estuviera asegurada. ¿Será Veer Popayán en 'nombre de todos los ciudadanos'? Para encontrar la solución socialmente más aceptada deberá haber coordinación profesional para enfocar las consultas correctamente y conformar reuniones con los ciudadanos más representativos. De esto nada se ha visto hasta la fecha. La costumbre es formar círculos cerrados o grupos con enfoques dispersos. Con esto surge otra pregunta que no ha sido contestada ni en el PEMP ni en la propuesta de Veer Popayán: ¿los ciudadanos que no son propietarios de inmuebles tendrán el mismo voto que los propietarios para tomar decisiones en la gestión de proyectos del centro histórico? ¿Los que aportan con capital tienen el mismo derecho que los que no aportan o aportan muy poco?

Por otro lado, ¿si los de poco capital tendrán poca influencia en las decisiones del ente gestor, pero representan las mayorías, cómo se asegura con una Sociedad por Acciones Simplificadas (SAS) la participación ciudadana con criterios de solidaridad e inclusión?

Luego de estas observaciones, Veer Popayán y la Fundación Amigos del Sabio Caldas se sumaron a la ardua labor de diseñar, junto con funcionarios de la alcaldía de Popayán y un equipo de profesionales conocedores del tema (que no necesariamente fueron veedores), la elaboración de la propuesta para la creación de un ente gestor para hacer andar el PEMP y desarrollarlo. Esta labor se consideró una meta por cumplir dentro del plan de desarrollo municipal.

Ante la evidente preocupación por la materialización de los proyectos del PEMP, se llega a la conclusión de que un ente gestor es factible solo a través de una base institucional fortalecida dentro de la administración municipal, que deberá tener diversas cualidades:

- Ser una entidad mixta público-privada que va a liderar el proceso de gestión requerido para poder cumplir los objetivos

- Ser una entidad que nazca con respaldo político y aprobación del Concejo Municipal

- Tener fuertes cimientos financieros, para lo cual, se deberán formular y gestionar varios proyectos de tal forma que tenga recursos propios

- Ser capaz de conciliar las relaciones sociales y comunitarias para poder atraer la opinión pública 
- Contar con un plan que se enraíce en la voluntad ciudadana

- Desarrollar el PEMP que será la 'Empresa de la Ciudad' encargada de rescatar y preservar el patrimonio de manera integral, y plantear alternativas para su recuperación y utilización como activo económico

Para la creación de este ente gestor se propone una alianza de carácter mixto público-privado; con visión de empresa moderna, económicamente autosostenible, y de alto perfil técnico y gerencial; enmarcada en un arreglo institucional necesario para el logro de una misión compleja (la implementación de un PEMP); y perfilada con una visión profundamente humanista para una ciudad que experimenta actualmente agudos procesos de transformación y destrucción de su patrimonio. Así está esbozado en el documento propuesto y preparado por Veer Popayán. Pronto quedará en manos del alcalde firmar el decreto que deje establecido el ente gestor que ejecutará el PEMP de Popayán, en la forma legal de una SAS de carácter mixto público-privado. Muchos opinan que sería el legado más grande y duradero que el alcalde Fuentes podría dejar a la Ciudad de Popayán.

Después de varias socializaciones y con el aval de la Administración Municipal, la Veeduría Ciudadana del Patrimonio Histórico y Natural de Popayán ha estado estudiando el tipo de empresa que se debe constituir. Los asesores en este campo han indicado que sea una SAS con capital público y privado, pero que el primero no exceda el $48 \%$ de las acciones. Podrán ser socios los ciudadanos que lo deseen, especialmente quienes tienen propiedades, empresas y negocios en el sector histórico, y en su zona de complementación.

Según expresa Sodemann (2015),

....durante el año 2015, el Gobierno Nacional se propuso promover una inversión significativa para equilibrar la relación centro-periferia. Es un momento histórico para el que se viene preparando la ciudad, ya que se planteó desarrollar iniciativas y propuestas que contribuyan a sacar el Cauca y Popayán del atraso, proceso que aún sigue pendiente. (párr. 4)

Con el ejemplo de Popayán, se estructuran algunas conclusiones, entre ellas que la conservación y protección de los centros históricos requiere decisiones técnicas, y estos necesitan soporte para mover los hilos de sus instrumentos de gestión y financiación. Lamentablemente, la ausencia y poca claridad de estos han soslayado la actuación de herramientas como el PEMP, que no debieran ser los receptores de las carencias de los POT, ni de los vacíos institucionales y legales.

Las realidades contemporáneas han puesto al patrimonio en un lugar de debate, y conflicto nacional e internacional. Para Colombia es vital la profundización en políticas específicas que permitan llevar a cabo una buena gestión, protección y salvaguardia del patrimonio. Los centros históricos y en general los lugares de la memoria cobran sentido cuando sus instituciones se articulan armónicamente, lo cual requiere, para obtener la confianza de sus ciudadanos preocupados, propuestas institucionales y técnico-financieras. También deben rodearse de equipos técnicos capaces de dirigir una empresa de economía mixta, de la cual van a formar parte todas las fuerzas públicas y privadas. Estas últimas son representativas y necesarias para poder usar una herramienta como el PEMP, cuyo objetivo principal es revitalizar, proteger y preservar el sector histórico de Popayán en función de una mejor calidad de vida para sus habitantes.

Colombia está haciendo un esfuerzo muy importante en cuanto a la reglamentación jurídica de su patrimonio, que debe ser reconocido no sólo dentro del ámbito nacional, sino fuera de él. Debe ser visto como ejemplo en cuanto a formulación de políticas públicas, cada vez mejor encaminadas, para la creación y recreación cotidiana del patrimonio cultural a través de su uso y apropiación comunitaria. 'En el camino se aprende', reza el dicho, y aún queda mucho por aprender y mucho trecho por recorrer en este claro ejemplo sobre manejo y gestión de los recursos patrimoniales. 
devenir Vol. 3, N6, JULIO-DICIEMBRE 2016, PP. 63-78 - EstUdIOS I ISSN 2312-7570

UNIVERSIDAD NACIONAL DE INGENIERÍA, LIMA

\section{Referencias}

Decreto Nacional № 4002 (2004). Constitución Política de Colombia.

Decreto Nacional № 4821 (2010). Constitución Política de Colombia.

Decreto Nacional № 763 (2009). Constitución Política de Colombia.

Ente. (2016). En Diccionario Oxford.

Isaza, J. (11 de octubre de 2014). ¿Hacia Dónde Vamos con el PEMP y su Ente Gestor?. El Tiempo. Recuperado de http://www.eltiempo.com/

Ley No 1185 (2008). Ley general de cultura (modifica y adiciona la Ley № 397 de 1997). Constitución Política de Colombia.

Ley № 163. (1959). Ley de defensa y conservación del patrimonio histórico, artístico y monumentos nacionales, Concejo de Monumentos Nacionales. Constitución Política de Colombia.

Ley No 388 (1997). Ley de Ordenamiento Territorial. Constitución Política de Colombia.

Ley No 397 (1997). Ley general de cultura. Constitución Política de Colombia.

López, A. (21 de agosto de 2015). Popayán frente a una decisión crítica para proteger su Patrimonio. Proclama del Cauca. Recuperado de http://www.proclamadelcauca.com/2015/08/ popayan-frente-a-una-decision-critica-para- proteger-su-patrimonio.html

Maya, M. (2014). El patrimonio de Popayán debe producir riqueza. La Campana. Recuperado de http://www.periodicolacampana.com/el-patrimonio-de-popayan-debe-producir-riqueza/

Ministerio de Cultura. (2010). Lineamientos de política para la recuperación de los centros históricos de Colombia. Bogotá, Colombia: Escuela Taller de Bogotá.

Ministerio de Cultura. (2011). Formulación e implementación de Planes Especiales de Manejo y Protección Bienes Inmuebles de Interés Cultural. Bogotá, Colombia. Escuela Taller de Bogotá.

Ministerio de Cultura. (2013). Patrimonio de la Humanidad en Colombia. Bogotá, Colombia: Lunwerg.

Montaña A. \& Frenchy L. (2012). Los Planes Especiales de Manejo y Protección para Centros Históricos y su incidencia en los principios de descentralización y autonomía de los municipios y distritos [Trabajo de tesis de especialización]. Facultad de Ciencias Jurídicas de Derecho Urbanístico de la Pontificia Universidad Javeriana. Bogotá. Recuperado de https://repository.javeriana.edu. co/bitstream/handle/10554/10029/FrenchyCelyLinaYanube2012.pdf?sequence=1

Olano, A. (27 de marzo de 2015). El sector histórico de Popayán es un valioso activo en el que se podrá invertir. La Campana. Recuperado de http://www.periodicolacampana.com/ustedpuede-ser-socio-del-que-sera-el-ente-gestor-del-pemp/

Pachajoa, M. (27 de abril de 2014). Urge Implementación del PEMP en Popayán. Red Patoja. Recuperado de http://mariopbe.com/a4pemp.htm

Sodemann, A. (11 de octubre de 2014). Propuesta Veer Popayán, aún sin respuesta. Red Payanesa. Recuperado de http://mariopbe.com/

Sodemann, A. (2015). Macro Proyecto Mesa-Larga/Plan Especial Del Manejo Del Patrimonio del Municipio de Popayán. Red Patoja. Recuperado de http://mariopbe.com/a4sod.htm 